\title{
Exploration on the Path of Emotional Identification of University Students in New Era on Socialist Core Values
}

\author{
Yinzhu LI \\ School of Business, Yuxi Normal University \\ Yuxi, Yunnan, 653100
}

\begin{abstract}
In order to improve the effectiveness of the socialist core value education for university students, the investigation finds that the socialist core value education in current colleges and universities focuses on identity education, and the ways (put forward in combination with the principle of emotional education) to promote the emotional identity of university students on the core values, including enhancing cognitive identity, promoting emotional training, eliminating negative emotion and other measures, thereby transforming cognitive identity into emotional identity and behavioral habits, promoting internalization of university students and maintaining core values.
\end{abstract}

Keywords-University students; Core values; Emotional identity and path

\section{INTRODUCTION}

Higher education shoulders the important task of cultivating socialist builders and successors developed morally, intellectually, physically and aesthetically, and the National Conference on Ideological and Political Work in Colleges and Universities was held in 2016, "profoundly clarifying the significance, target positioning, main tasks and basic requirements of strengthening and improving ideological and political works in colleges and universities from the global and strategic perspective and being programmatic documents guiding the ideological and political works of colleges and universities under the new situations". [1] The colleges and universities must adhere to the correct political direction and comprehensively implement the Party's educational policy. The socialism thought with Chinese characteristics in the new era is the latest achievement of the localization of Marxism in China and an important component of the theoretical system of socialism with Chinese characteristics, the new era has put forward new requirements for the ideological and political works of colleges and universities and integrated the socialism with Chinese characteristics in the new era into the ideological and political education on university students, which can help guide university students to better understand cultural connotations and establish correct values.

\section{The VAlue of Socialist CoRE VAlue EduCATION}

The socialist core values reflect the rich connotation and practical requirements of the socialist core value system and are also the highly concise and concentrated expression of the socialist core value system. Since the 18th National Congress of the Communist Party of China, the central government has attached great importance to cultivating and practicing the socialist core values. General Secretary Jinping XI has made important statements and clear requests on many occasions. The Political Bureau of the Central Committee of the CPC has attended the learning collectively around cultivating and promoting the socialist core values and promoting the traditional Chinese traditional. [2] The General Office of the Central Committee of the Communist Party of China issued the Opinions on Cultivating and Practicing the Socialist Core Values, and the greater importance and vigorous deployment from the Party Central Committee has pointed out the direction of efforts to strengthen the socialist core value education and practice and provided important provisions to be followed.

On October 18, 2017, Comrade Jinping XI pointed out in the reports of the 19th National Congress of the Communist Party of China that "the socialist core values should be nurtured and practiced. We must focus on cultivating new people in the era of national rejuvenation, strengthen the education guidance, practice cultivation and institutional guarantee, give play to the leading role of socialist core values in national education, spiritual civilization creation and spiritual and cultural product creation, production and propagation, integrate the socialist core values into all aspects of social development and transform them into people's emotional identity and behavioral habits" [3].

On November 8, 2012, Jintao HU stated in his reports of the 18th National Congress of the Communist Party of China that "we must adhere to taking the cultivation of people as the foundation and moral education as the first priority, focus on the core tasks of strengthening moral education and cultivating people, include the socialist core values into the overall national education planning, make them run through all areas including basic education, higher education, vocational and technical education and adult education, implement them into all aspects including education, teaching and management services to cover all schools and educated people, form an 
education platform integrating with classroom teaching, social practice and campus culture, constantly improve the excellent traditional Chinese culture education, form an effective form and long-term mechanism for loving learning, loving labor and loving the motherland and strive to cultivate socialist builders and successors developed morally, intellectually, physically and aesthetically" [4].

The 2016 National Conference on Ideological and Political Work in Colleges and Universities put forward that the colleges and universities must adhere to the direction of socialist education and follow four-"adhere to" including "adhering to persistently cultivating and promoting the socialist core values". As the main force of the younger generation, the development of the socialist core value education by the university students can help colleges and universities to realize the essential goal of strengthening moral education and cultivating people, promote university students to adhere to the correct political direction in the development of society in the new era, better understand the status quo of the socialist core value education, strengthen the ideals and beliefs and promote the harmonious development and stability of society.

\section{THE PRINCIPLE OF EMOTIONAL IDENTIFICATION OF UNIVERSITY STUDENTS ON SOCIALIST CORE VALUES}

Emotion is the subjective experience associated with the social needs of the people, and it is one of the unique psychological phenomena of human beings. There are roughly three kinds of emotions in terms of their forms. The first is the intuitive emotional experience, when a certain situation is perceived, a positive or negative emotional experience will be produced, such experience is often closely related to previous experience and moral orientation, thus an intuitive emotional experience will be produced in a specific atmosphere and an orientation of moral behavior will be quickly made. For example, in terms of the performance of some heroes in the rescue situation, they may be not allowed to think more under the circumstances at that time. The second is the emotional experience associated with the specific moral image, i.e. the emotions that act through imagination and image, such as the emotions of loving the country and loving the people from historical figures, the moral image has played a transforming role from perceptual cognition to the rational cognition, and these images can promote university students to better understand ethics. The image is not necessarily a figure, such as a TV program for patriotic education, but also a visual education. The third is the emotional experience realizing the moral theory, which is an emotion with the clear realization of ethical requirements as the intermediary and also a very generalized but higher-level emotion, i.e. a sublimated moral cognition. Such as the emotional experience produced after true realization of the relationship between the individual and the motherland and the obligations to the motherland. Therefore, to know him is to love him. "It is a kind of longlasting emotion with powerful motivation. The Lovely China written by the martyr Zhimin FANG is a concentrated reflection of this kind of emotion" [5].
Identity is the recognition, acceptance, approval and support of individuals to others. Freud believes that "emotional identity is the process by which an individual imitates the value or norm of another person or group, becomes internalized and forms his own behavioral pattern, and it is also the original form in which the individual has an emotional connection with others" [6]. The educational theory holds that emotion is "the inner experience caused by whether human needs are realized or not, and it is the internal motivation to promote people to produce moral behavior or to stop unethical behavior together with cognition" [7]. The emotional identity is the process by which an individual recognizes and imitates the attitudes, thoughts, emotions, and behaviors of others or groups and becomes assimilated with them [7].

The reports of the 19th National Congress of the Communist Party of China clearly require "incorporating socialist core values into all aspects of social development and transforming them into people's emotional identity and behavioral habits" [8]. Emotional identity is the internal motivation of cognitive identity and behavioral identity, the further deepening of cognitive identity and also the emotional basis of behavioral identity. The individuals who have an emotional identity on the socialist core values will subjectively establish an affirmative and satisfactory emotional attitudes and stable emotional attitudes toward socialist core values, may have an emotional struggle (such as no need, disagreement and self-resistance) against the phenomenon that is contrary to the socialist core values and take convincing, necessary and reasonable actions consistent with core values.

At present, the socialist core value education in colleges and universities mainly focuses on cognitive education, i.e. explanation rather than experience, and there is not much education on emotional identity. However, the emotional training is closely related to the cognitive education, the emotion is the direct cause of behavior, and without positive emotions, it will be not easy to produce strong identity or even stable behavior. The individuals can truly practice core values only if they can identify and internalize the educational contents and have the emotional resonance.

\section{THE PATH OF EMOTIONAL IDENTIFICATION OF UNIVERSITY STUDENTS ON SOCIALIST CORE VALUES}

\section{A. The connotation of emotional identity}

Canadian sociologist Charles. Tayler believes that the recognition is "the confirmation on how to communicate in order to fully plays the role of the individual, that is, it is a worthwhile and important for the individual to make judgement, distinguishing and confirmation [9]. Therefore, the emotional identity includes two levels; one is the individual's consent or approval from the self-social role or identity. Another is the individual's emotional initiative and stability on maintenance and belief formed from the perspective of social interaction and social identity. The emotional identity of the socialist core values is firstly manifested as the university students' recognition and approval emotions on the connotations of their social roles based on their understanding, in order to meet their social role requirements as university students; Secondly, it is also manifested their deep understanding on the socialist core 
values and strong attitude towards values such as not only complying with personal expectations and social requirements, but also loyally, actively and consciously safeguarding the socialist core values, treating all individuals and groups equally and consciously abiding by and safeguarding the socialist core values.

\section{B. Exploration on the Path of Emotional Identity of University Students on Socialist Core Values}

The current university students (mainly after 1995), as the complete beneficiaries of the reform results, the priority experiencers in the information age and the witnesses of the construction of a harmonious society, have the following characteristics: active thinking, highlighted self-centeredness, open mind, weak psychological enduring capacity, lofty goal, obvious utilitarian behavior, passion and weak sense of teamwork, which are an important basis for promoting their selection of the path of emotional identity on socialist core values.

(1)Enhance cognitive identity. Cognitive identity is the basis of emotional identity, which must follow the requirements of running ideological and political works through the whole process of education and teaching, integrating the contents and cases of socialist core values into classroom teaching, combining patriotic education, ideal and belief education and outlook education on life values with the teaching objectives of professional courses fully rather than only in the regular ideological and political curriculum, and guiding students to think and recognize the values such as prosperity, democracy, civilization, harmony, freedom, equality, justice, rule of law, patriotism, dedication, integrity and friendliness when teaching professional knowledge. The colleges and universities must also change the abstract education of socialist core values to concrete education, change the boring education to vivid education, and extend the students' understanding of the teaching modal objective while increasing the vivid and political nature of the classroom. Therefore, the student can learn scientific knowledge and experience humanistic spirit simultaneously. When talking with and conducting ideological and political education on students, the counselors should fully integrate the socialist core values into the process of solving students' ideological confusion and practical difficulties and improve students' cognitive identity from the healthy growth and personality improvement of students. Simultaneously, they should also inherit the positive energy and subtly develop the core value education via various self-media platforms in combination with the psychological and behavioral characteristics of university students.

(2) Promote the cultivation of moral emotions. It is necessary to pay attention to the creation of the healthy and positive public opinion and campus environment, such as posting the displayed iconic propaganda contents, in order to promote university students to produce an intuitive emotional experience in a specific atmosphere. "An advanced emotion associated with moral theory emotion can be upgraded from a specific emotion after continuous generalization and depending on the basis of the students' intuition and specific emotion" [10], For example, to cultivate patriotic feelings, it is also necessary to base on the cultivation of specific emotions such as loving parents, loving hometown, loving people in the hometown and loving the national flag, and then rise to the cultivation of emotional experience such as responsibility for the motherland and the relationship between the individual and the state. It is also necessary to make full use of artistic works, literary and artistic images to establish and publicize positive models, disseminate programs on related themes, and promote the transition of university students' understanding on values from the perceptual understanding to the rational understanding and make them have emotional resonance of core values.

(3) Control the elimination of negative emotions. In the cultivation of moral emotions, the teachers should pay attention to observing students' attitudes and emotional performances, discover the emotional obstacles of students in cultivating morality in a timely manner and try to eliminate them. If excessive emotional performance is caused by insufficient correct cognition and attitude, it may be a kind of negative emotion. For example, someone is happy with the achievements of the individual, it is normal to celebrate the honors that the school has achieved, however, if someone is arrogant and devalued in front of other students and schools due to his or her achievements or event teases others, it may be an appropriate behavior. It is necessary to train students to be good at controlling and regulating their emotions and to express them reasonably. In addition, if the method adopted by the teacher is not suitable for the students, the attitude is blunt, etc., the mandatory requirements or the disharmonious daily relationship and the contradiction between the inner experience of the students in the moral practice and the ethical norms may lead students to become indifferent and refuse to implement them under the premise of knowing that it should be implemented and lead to the production of negative emotions and even emotional disorders. The teachers should overcome negative emotions in view of the reasons or overcome negative emotions by grooming, interpreting, paying attention to relationship coordination, improving work styles or using positive emotions. For the immoral emotions, their consequences must be analyzed so that the students can improve their ability to regulate and control their emotions while recognizing these consequences.

\section{CONCLUSION}

The education of emotional identity on socialist core values can achieve university students' cognitive identity and internalization of core values through emotional means and transform them into self-regulation norms, thereby promoting the initiative and stability of their behaviors, practicing the core values and improving the effectiveness of the cognitive education. 


\section{REFERENCES}

[1] Hui HE. Improvement and Strengthening of Remote and Open Education of Ideological and Political Works According To the Actual Situations [J]. Journal of Tianjin R \& TV University. December, 2017.

[2] Jianmei YANG. Honesty - the Cornerstone of Building a Traditional Virtue Education System [J]. Education and Teaching Forum. July, 2018

[3] Kunming HUANG. Cultivation and Practice of the Socialist Core Values [J]. Research on Ideological and Political Works. December, 2017

[4] Yongsheng Liu. Discussion on Cultivation and Practice of the Socialist Core Values [J]. Journal of Ningxia University. November, 2017.

[5] Xueli GUO. Exploration on Emotional Education in Chinese Teaching [J]. New Course (Middle School Version). August, 2007.

[6] Huayong YAN. Discussion on the Behavioral Identity on Socialist Core Values [J]. Journal of Guiyang University (Social Science Edition). December, 2017.

[7] Chunxing ZHANG. Zhang's Dictionary of Psychology [C]. Shanghai: Shanghai Lexicographical Publishing House, 122.

[8] Jinping XI. Secure a Decisive Victory in Building a Moderately Prosperous Society in All Respects and Strive for the Great Success of Socialism with Chinese Characteristics for a New Era -- Reports of the 19th National People's Congress of the Communist Party of China. Research On the Political Work of Oil. November, 2017.

[9] Qing TAO. Charles Tayler Modern Identity: Finding the Human Nature in the Inner Self. [J] Seeking Truth, April 2005,

[10] Wenbin QI. Give Consideration To Every Piece of Wood Board [J]. Education and Teaching Forum September 2011. 